\title{
How are Enterprise Architecture Design Principles Used?
}

\author{
Robert Winter \\ Institute of Information Management \\ University of St. Gallen \\ St. Gallen, Switzerland \\ robert.winter@unisg.ch
}

\author{
Stephan Aier \\ Institute of Information Management \\ University of St. Gallen \\ St. Gallen, Switzerland \\ stephan.aier@unisg.ch
}

\begin{abstract}
Most agree that enterprise architecture (EA) artifacts include not only representation models, but also design principles [35]. While EA modeling and EA models are covered broadly in the EA state-of-the-art, design activity issues and design principles in particular are still neglected. While there has been some work on EA principles recently, their use has not been systematically surveyed so far. This is surprising because EA principles play an important role in practice. Based on a review of the state-of-the-art of EA principle understanding, we summarize findings from a survey among 70 participants from Swiss and German companies. While EA principles are widely defined, well documented, based on IT strategy and generally perceived as useful, deficiencies are apparent regarding stakeholder involvement, business architecture principles (definition as well as usage), regular principle reviews, and business alignment.
\end{abstract}

Keywords-enterprise architecture, design principles, survey

\section{INTRODUCTION}

According to IEEE standard 1471-2000 for software intensive systems [17] and its adaptation to enterprise architecture (EA) by The Open Group [35], architecture is defined as (1) "[t]he fundamental organization of a system embodied in its components, their relationships to each other, and to the environment", and as (2) "the principles guiding its design and evolution" [17]. The (1) fundamental organization of a system is often represented by models of the as-is state or the to-be state of a system [2, 5, 24]. For these purposes, metamodels, methods, and frameworks have been developed and extensively discussed in literature [27, 32, 33]. However, (2) activities, rules, and particularly principles guiding an architecture's design and evolution from an as-is state into a to-be state are often neglected and thus are hardly covered in literature. Stelzer's [34] TEAR 2009 review of EA literature identifies only six publications that specifically address $E A$ design principles. The neglect of principles and guidelines for EA is surprising because e.g. Hoogervorst [15] or Dietz [9] see principles and guidelines as the core of architecture design.

Initial interviews with practitioners indicated, that EA design principles are a well understood area of managing transformation in companies as described for instance in the Open
Group's architecture compliance review method proposed in TOGAF 9 [35]. However, further analyses of case studies, have revealed that only a very few organizations have a consistently used and managed set of EA design principles in place for reviewing transformation projects based on such design principles.

Only recently, Fischer et al. [13] and Aier et al. [1] consolidate the different EA design principle definitions into one EA design principle meta-model. The consolidated metamodel allows to create a common understanding among company representatives and researchers about what an EA design principle is, compare EA design principle's usage across companies and consolidate survey results into a report on how EA design principles are currently used. The paper at hand reports on first results from a survey actually aiming at understanding definition, use, enforcement, and management of such principles in companies. These results do not only close a gap in practice literature, but also provide a starting point for researchers that aim at improving EA design principle related practices.

The paper is structured as follows: In section two, the consolidation of EA principle definitions is summarized. In section three, the survey and the obtained results are documented. In section four, we discuss our results and outline further research.

\section{WHAT IS AN EA DESIGN PRINCIPLE?}

In this section we review related work in order to derive a sound definition of an EA design principle. We present this definition in the form of a meta-model. Additionally we extend our meta-model by elements describing an EA principle's environment. This extended definition serves a basis for an empirical study which we present in section 3 .

Stelzer's [34] literature review identifies eleven articles on EA principles. His analysis differentiates EA design principles from EA representation principles. EA design principles refer to the rules a system's organization should follow while EA representation principles refer to attributes of the models of the respective system. Examples for representation (or syntactic) principles are understandability, consistency, and unambiguousity [25, 34]. As EA representation principles are out of scope of this publication, we exclude all 
papers that solely refer to EA representation principles and focus on EA design principles only. ${ }^{1}$

Based on Fischer et al.'s [13] discussion and comparison of the six remaining articles that is summarized in Table 1, Aier et al. [1] uncover communalities and derive a consolidated meta-model. Their consolidation is summarized in the following.

Except Richardson et al. [31], authors mix definitions of an EA principle itself with definitions of an EA principle in its environment. For reasons of transparency Aier et al. first consolidate definitions of an EA principle itself (core definition) and then extend this core definition by covering the impact that it has on its environment (extended definition).

TABLE I. EA DESIGN PRINCIPLE DEFINITIONS [13]

\begin{tabular}{|c|c|c|}
\hline Reference & Method & Principle definition \\
\hline $\begin{array}{l}\text { Richardson, } \\
1990 \text { [31] }\end{array}$ & $\begin{array}{l}\text { case } \\
\text { study }\end{array}$ & $\begin{array}{l}\text { "Principles are an organization's basic } \\
\text { philosophies that guide the development } \\
\text { of the architecture. ... Principles provide } \\
\text { guidelines and rationales for the constant } \\
\text { examination and re-evaluation of technol- } \\
\text { ogy plans." (p. 389) }\end{array}$ \\
\hline $\begin{array}{l}\text { Armour, } \\
1999 \text { [3] }\end{array}$ & $\begin{array}{l}\text { concep- } \\
\text { tual }\end{array}$ & $\begin{array}{l}\text { "... simple, direct statements of how an } \\
\text { enterprise wants to use IT. These state- } \\
\text { ments establish a context for architecture } \\
\text { design decisions by translating business } \\
\text { criteria into language and specifications } \\
\text { that technology managers can understand } \\
\text { and use. Architecture principles put boun- } \\
\text { daries around decisions about system } \\
\text { architecture." (p. } 38 \text { ) }\end{array}$ \\
\hline $\begin{array}{l}\text { Hooger- } \\
\text { vorst, } \\
2004[15] \\
\end{array}$ & $\begin{array}{l}\text { concep- } \\
\text { tual }\end{array}$ & $\begin{array}{l}\text { no explicit definition, "collectively the } \\
\text { design principles are identified as enter- } \\
\text { prise architecture" (p. } 217 \text { ) }\end{array}$ \\
\hline $\begin{array}{l}\text { Chen, } \\
2004 \text { [7] }\end{array}$ & $\begin{array}{l}\text { concep- } \\
\text { tual }\end{array}$ & $\begin{array}{l}\text { "Architecting principles are rules to use } \\
\text { when elaborating enterprise architec- } \\
\text { tures." (p. 1214) }\end{array}$ \\
\hline $\begin{array}{l}\text { Wilkonson, } \\
2006 \text { [37] }\end{array}$ & $\begin{array}{l}\text { case } \\
\text { study }\end{array}$ & no explicit definition \\
\hline $\begin{array}{l}\text { Lindström, } \\
2006 \text { [25] }\end{array}$ & $\begin{array}{l}\text { case } \\
\text { study }\end{array}$ & $\begin{array}{l}\text { "Architectural principles define the under- } \\
\text { lying general rules and guidelines for the } \\
\text { use and deployment of all IT resources } \\
\text { and assets across the enterprise ..." (p. 2) }\end{array}$ \\
\hline
\end{tabular}

\section{A. Core Definition}

Richardson et al. [31] mention two important aspects of an EA design principle: (1) A rationale explaining how the principle is meant to work and why the principle is defined. (2) Implications that the principle has to the enterprise. Specifically implications state how relevant system stakeholders are affected by the principle. Hoogervorst $[15,16]$ re-uses the components defined by Richardson et al. [31] and adds key actions, i.e. concrete guidelines for implementing the principle. Additionally key actions aim at providing the necessary conditions, such that the architecture principles can

\footnotetext{
${ }^{1}$ In the following we use the short versions principle or $E A$
} principle referring to an EA design principle. be followed. Armour et al. [3] propose another way to refine architectural principles as standards profile and technical reference models. As far as the standards profile is concerned, we prefer the more extensive proposition by Richardson et al. [31] and Hoogervorst [15, 16].

Furthermore Hoogervorst $[15,16]$ as well as Lindström [25] introduce the principle statement. Their description implies that the statement is part of the principle. Lindström [25] also mentions measures as an important part of an EA principle in order to be able to evaluate a principle's efficacy, thus the fulfillment of the statement, and finally to support the process of managing (introducing, evaluating, changing, and revoking) EA principles. Fig. 1 illustrates the core components of an EA design principle in a meta-model.

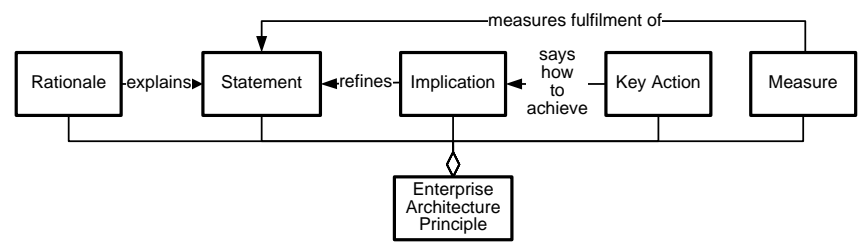

Figure 1. EA principle and its components

To further specify the nature of an EA design principle, it is helpful to understand the principle's impact on its environment. In a first step, Aier et al. [1] build the basic structure of the extended meta-model. In a second step, this basic structure is refined based on the different foci taken by the authors of the discussed related work.

\section{B. Basic extensions}

As with every design the question of where to begin is a difficult one. Aier et al. [1] start with an exploratory focus group $[14,26]$. The aim of the focus group has been to understand EA principles' role in the development and advancement of EA. The participants of the focus group were practitioners that are experts in the field of EA and have experience managing and using EA principles. The focus group had nine participants from seven different companies based in Germany and Switzerland plus the focus group's moderator.

Fig. 2 illustrates the relations between EA transformation project, to-be EA and as-is EA that resulted from the focus group results. A defined to-be EA requires for certain $E A$ principles in order to be achieved by EA transformation projects. Therefore EA principles also have to restrict an EA transformation project's freedom of choosing a design in order to ensure a development towards the to-be EA. Finally there may also be EA principles that restrict the possible tobe EAs. 


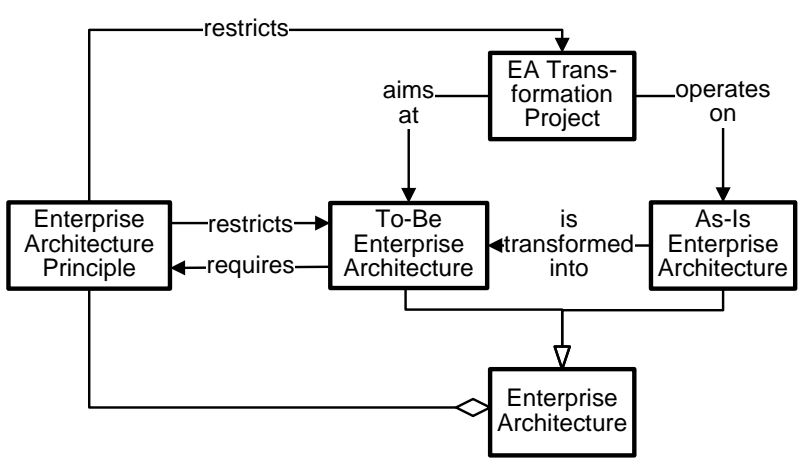

Figure 2. Role of EA principle in its environment

\section{Refinement of basic extensions}

Based on the basic extensions resulting from the focus group, Aier et al. [1] aim at consolidating the different definitions of EA principle in the analyzed publications.

Armour et al. [3] introduce the notion of a model of a system. In order to cover the differences between an enterprise and its model, we have fundamentally extended the basic model and put the enterprise into its center. We diffe- rentiate between an existing enterprise and a target enterprise for an EA transformation project. An EA transformation project begins to operate on the existing enterprise while aiming at changing it such that the target enterprise is realized.

EA principles give advice on how to design the target architecture by restricting the design freedom of EA transformation projects $[8,9,15,16]$. In accordance with Dietz [8, 9], Hoogervorst $[15,16]$ differentiates a functional view and a constructional view on an enterprise. Whilst the functional view (teleological view, black box view) deals with the purpose or goal of a system, the constructional view (ontological view, white box view) is about how the system's functions are brought to life [8]. In contrast to business requirements referring to the functional view of projects, architecture design principles refer to the constructional view of the project $[15,16]$.

Different authors propose different architecture layers. Whilst Hoogervorst $[15,16]$ proposes a business architecture, an organization architecture, an information architecture, and a technology architecture, Armour et al. [3] propose a business view, a function view, a work view, an information view, and an infrastructure view. Winter and Fischer

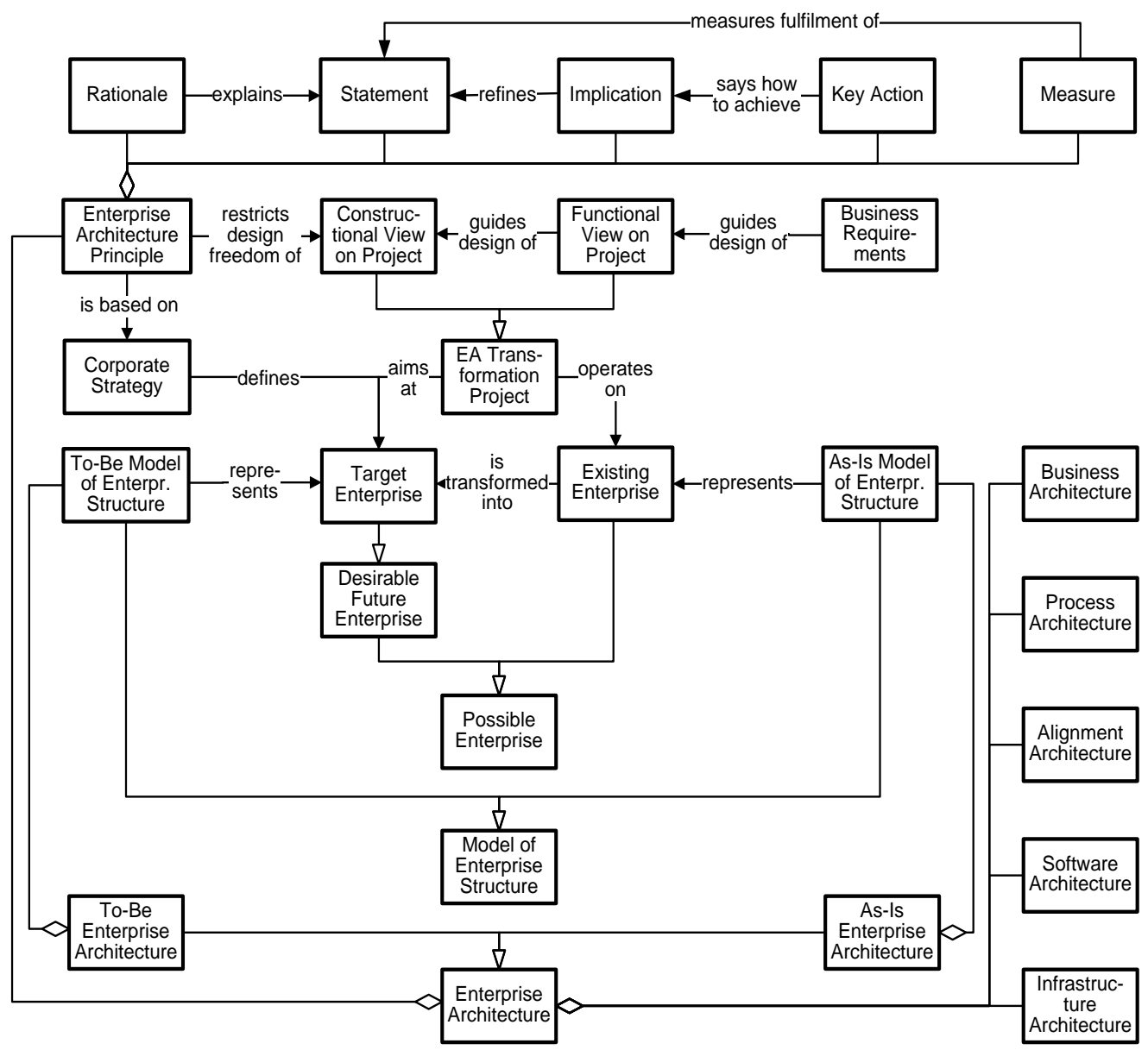

Figure 3. Consolidated definition of EA principle in its environment [1] 
[38] consolidated a variety of EA frameworks and identified five essential architectures: a business architecture, a process architecture, an alignment architecture, a software architecture, and an infrastructure architecture. As Fischer and Winter [38] already consolidated the understanding of different layers, we adopt their proposition in our definition.

The structure of an enterprise can be represented in a model: the existing enterprise in an as-is EA model, the target enterprise in a to-be EA model. In accordance with the architecture definition in the IEEE Std. 1471-2000 [17], both the models of the enterprise structure and the architecture principles form the architecture.

As the main input for an EA principle Armour as well as Wilkinson [37] and Lindström [25] highlight the influence of corporate strategy. Fig. 3 illustrates the resulting consolidated definition of EA principle in its environment.

\section{HOW ARE EA PRINCIPLES USED?}

Based on a common understanding which is created by a consolidated definition of an EA principle in its environment, we used an EA practitioner conference to collect data on EA principle usage in companies. This problem - the definition, usage, management, and enforcement of EA principles in organizations - is poorly understood. There is no $a$ priori theory to explain the phenomenon. Consequently, this paper is of the exploratory theory-creating rather than theorytesting kind. We argue with Iivari and Huisman [18] that "even though theory-creating research is sometimes associated with qualitative and interpretive research methods rather than with quantitative ones [19], we do not see any philosophical [6] or methodological $[10,36]$ reasons why this should be so". Iivari and Huisman [18] point out that the relationship between the purpose of a piece of research (exploratory/theory-creating versus confirmatory/theory-testing) and its methods are orthogonal. Therefore this paper employs a survey as its explorative research method.

\section{A. Questionaire and data collection}

Data was collected by means of a questionnaire that comprised five sets of questions:

1. General context of the company (industry, size, experience with EA, role of respondent in company, etc.)

2. Cultural characteristics that might have an influence on EA setup and EA success (not reported in this paper)

3. Current positioning of EA in company (stakeholders, delivered and used EA services, etc.; not reported in this paper)

4. 19 questions regarding EA principle definition, use, management, and enforcement

5. EA value perception in company (not reported in this paper)

Regarding EA principle usage, table 3 exhibits for which usage aspects the respondents were asked to characterize their company's current implementation level on a 5-level Likert scale ranging from "not at all" (1) through "completely" (5).
TABLE II. EA PRINCIPLE PRINCIPLE DEFINITION, USE, MANAGEMENT, AND ENFORCEMENT QUESTIONS

\begin{tabular}{|l|l|}
\hline P.01 & $\begin{array}{l}\text { Architecture principles are defined for our business archi- } \\
\text { tecture }\end{array}$ \\
\hline P.02 & Architecture principles are defined for our IT architecture \\
\hline P.03 & $\begin{array}{l}\text { Architecture principles are applied for business architec- } \\
\text { ture }\end{array}$ \\
\hline P.04 & Architecture principles are applied for IT architecture \\
\hline P.05 & $\begin{array}{l}\text { Architecture principles are defined together with all rele- } \\
\text { vant stakeholders }\end{array}$ \\
\hline P.06 & $\begin{array}{l}\text { Architecture principles are defined centrally and ap- } \\
\text { proved by senior management }\end{array}$ \\
\hline P.07 & Architecture principles are observed \\
\hline P.08 & $\begin{array}{l}\text { It is difficult to enforce the observance of architecture } \\
\text { principles. }\end{array}$ \\
\hline P.09 & $\begin{array}{l}\text { There are many exceptions where architecture principles } \\
\text { are overruled/not applied }\end{array}$ \\
\hline P.10 & $\begin{array}{l}\text { The exception process for architecture principles is de- } \\
\text { fined }\end{array}$ \\
\hline P.11 & $\begin{array}{l}\text { Architecture principles are checked for usefulness on a } \\
\text { regular basis }\end{array}$ \\
\hline P.12 & $\begin{array}{l}\text { Architecture principles are updated (extended, amended, } \\
\text { deleted) on a regular basis }\end{array}$ \\
\hline P.13 & $\begin{array}{l}\text { The implementation level of architecture principles is } \\
\text { measured on a regular basis }\end{array}$ \\
\hline P.14 & $\begin{array}{l}\text { Architecture principles lead to a higher architecture quali- } \\
\text { ty } \\
\text { P.15 }\end{array} \begin{array}{l}\text { Architecture principles are documented in a well accessi- } \\
\text { ble way }\end{array}$ \\
\hline P.16 & $\begin{array}{l}\text { Architecture principles include an explanation why they } \\
\text { should be observed }\end{array}$ \\
\hline P.18 & $\begin{array}{l}\text { Architecture principles include a description how they } \\
\text { should be applied }\end{array}$ \\
\hline Architecture principles are based on our IT strategy \\
\hline Architecture principles are based on our business strategy \\
\hline
\end{tabular}

Despite the explorative character of our study the 19 questions are (1) based on our extended definition of EA principle in its environment and are (2) targeted at understanding the way principle definition influences principle's effectiveness and enforcement.

Items P.01-P.04 ask for the definition and usage of principles for partial architectures. Although our definition differentiates five partial architectures, we found a more coarsegrained differentiation of business and IT architecture to be appropriate. Items P.05/P.06 address the organizational configuration of principle definition. Items P.07-P.10 address principle enforcement. Items P.11-P.13 address principle measurement and management as stated in our core definition. Item P.14 addresses principle effectiveness. Items P.15P.17 address principle and principle components documentation. Items P.18/P.19 finally address the role of IT and business strategy for principle definition as stated in our model.

We pre-tested the questionnaire with practitioners from six of our regular research partner companies. The pre-test resulted in minor adjustments of the wording. Questionnaires from the pre-test are not included in the sample. 
Our data analysis is ongoing. Although the analysis of question sets three and five will yield an even more differentiated analysis on the position and usage of principles for EA management as well as of their effectiveness, the first explorative analysis presented here already provides an interesting stating point.

A total of 70 questionnaires were returned and coded. While we cannot claim our sample to be representative, respondents have a strong link to EA because all of them are participants of an EA practitioner conference. We cannot identify the number of organizations respondents come from without sacrificing the respondent's anonymity. By analyzing the conference's list of participants, we can, however, state that the potential number of multiple questionnaires referring to the same organization is very small. While a single questionnaire per participating organization might not necessarily reflect the actual situation in a specific organization, the entirety of filled questionnaires, however, supports explorative statements on EA principle usage in the (not representative) sample indicating the situation in companies in Germany and Switzerland.

\section{B. Descriptive survey results}

40 respondents characterized themselves as IT service users and 30 as IT service providers. 57 respondents assigned themselves to an IT unit and 7 to a business unit.

Primarily representatives of large organizations participated in the survey (fig. 4). 28 respondents came from large companies (5000 employees and over), 20 from medium large companies (1000-5000 emp.), 13 from medium sized companies (100-1000 emp.) and 9 from small companies (100 emp. or less).

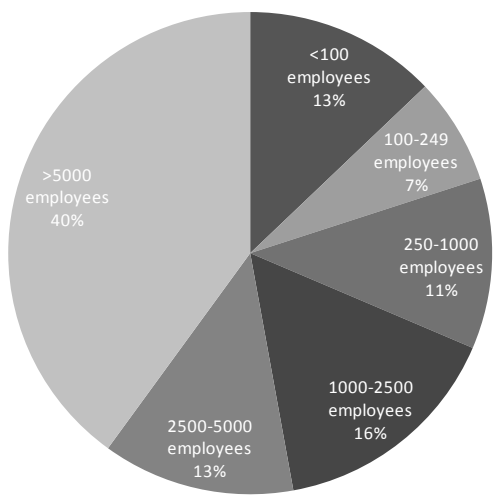

Figure 4. Distribution of size of organizations participating in the survey

The majority of survey participants are well experienced in the field of EA (fig. 5). 24 respondents reported long EA experience ( 5 years or more), 18 two to five years and 20 two years or less.

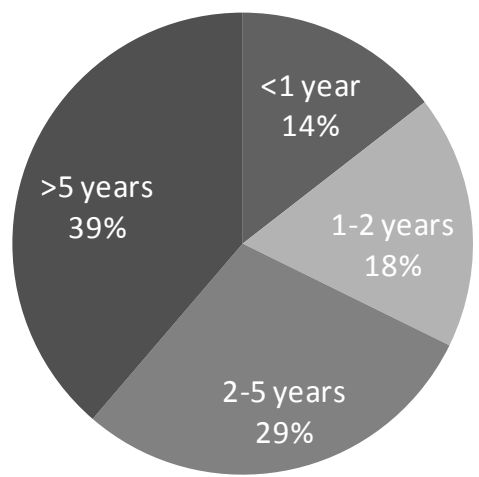

Figure 5. Distribution of EA experience of organizations participating in the survey

22 respondents stated they are actively involved in EA, 20 actively in business architecture and 51 actively in IT architecture.

Survey participants are broadly distributed among industries (fig. 6). The most frequently reported industries in the survey are banking (16), software/IT (15) and insurance (13), followed by telecommunications (8) and public services (7).

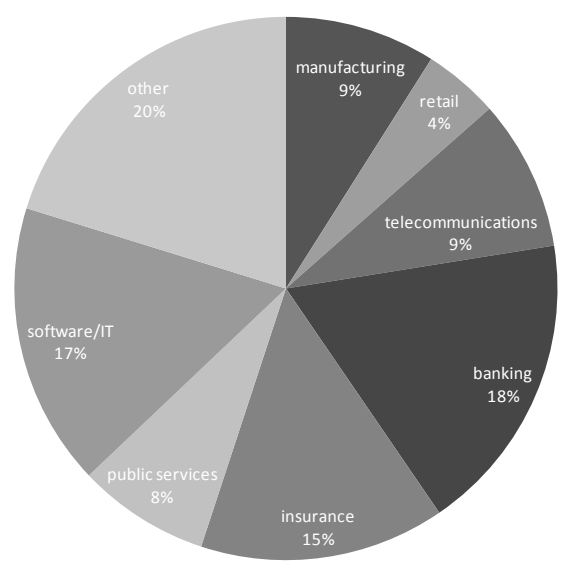

Figure 6. Industry distribution of organizations participating in the survey

Our first analyses deliver some interesting insight in how EA principles are currently used in organizations, which EA principle related disciplines organizations have a good command of, and which areas need to be improved. Fig. 7 illustrates the descriptive statistics of the core survey observations. For each item listed in table 2 the respective mean value as well as the standard deviation are given.

First analyses of the observations show that principles regarding IT architecture are rather well defined, equally well applied, and well founded in IT strategy (items P.02, P.04, P.19). The EA principles' business perspective, however, is much less defined and even less applied (items P.01, P.03), business strategy has a rather low impact. While this result may not be surprising - given EA's roots in IT departments and its slow development towards more business oriented applications - it is a tenuous situation given the results of the more in depth regression analysis we present later on. 
The difficulties regarding the enforcement of EA principles (item P.08, highest of all values) seem to be related to the inability to measure EA principle implementation (item P.13, third lowest value). Low values for the involvement of relevant stakeholders and for regular usefulness checks also contribute to the low extent and low usage of EA principles from a business perspective. If the business side was better involved, comparably high values for central definition/maintenance, senior management support and therefore also observance let expect that useful effects could be achieved not only for IT architecture management. Values for exception handling, documentation and explanation are in the middle range. A slightly below average value for application advice indicates that a central EA principle management approach sitting close to the IT unit could benefit from more application orientation in addition to being closer to the business units.

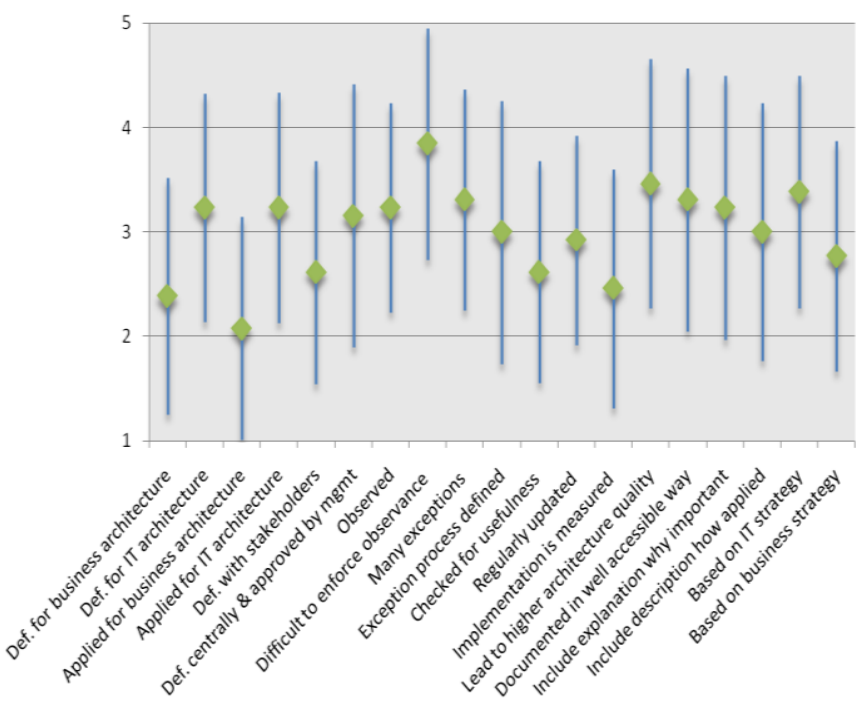

Figure 7. Descriptive survey results

\section{Exploration of relationships}

While the first analyses already give an overview on the state of definition, usage, and management of EA principles, they do not provide much insight on the relationships between the items and thus provide not much guidance on how to further develop EA principles in organizations. Therefore we have performed a correlation analysis among these items and a number of explorative (stepwise) multiple regression analyses. Since regression analyses have a much stronger explanatory power, we report on the latter in the following.

We first analyzed the possible drivers (independent variables) for an improved architecture quality (dependent variable). Our explorative regression analysis identifies three drivers for an improved architecture quality (table 3 ). The first driver of course is that principles need to be observed. The second driver is that principles are regularly updated and the third driver is that principles should be based on business strategy. Especially the last aspect is interesting - not only because that item is currently not very well implemented, but also because there is no respective relation to IT strategy. All three relations are decidedly positive. The goodness of fit is represented by the adjusted $\mathrm{R}^{2}$ achieving a good value (.633, table 5). The $\mathrm{F}$ test in table 4 shows that the null hypothesis (there is no relation between the dependent variables and the independent variable) clearly has to be rejected for the entire model. Finally we have performed a $t$ test for all coefficients individually. Here the null hypothesis has to be clearly rejected, too (table 3). Furthermore we have tested for heterogeneity of variance, autocorrelation, and multi-collinearity without indication.

TABLE III. DRIVERS FOR AN IMPROVED ARCHITECTURE QUALITY

\begin{tabular}{l|ccc}
\hline \multirow{2}{*}{$\begin{array}{l}\text { Model } \\
\text { (dependent variable: Higher } \\
\text { architecture quality) }\end{array}$} & $\begin{array}{l}\text { Standardized } \\
\text { Coefficients }\end{array}$ & & \\
\cline { 2 - 3 } & Beta & $\boldsymbol{t}$ & Sig. \\
\hline EAP observed & .341 & 3.427 & .001 \\
EAP regularly updated & .256 & 2.798 & .007 \\
EAP based on business & .394 & 4.373 & .000 \\
strategy & & & \\
\hline
\end{tabular}

TABLE IV. MODEL QUALITY (F TEST) FOR DEPENDENT VARIABLE IMPROVED ARCHITECTURE QUALITY

\begin{tabular}{l|rrrrr}
\hline Model & $\begin{array}{l}\text { Sum of } \\
\text { Squares }\end{array}$ & $\boldsymbol{d} f$ & Mean Square & $\boldsymbol{F}$ & Sig. \\
\hline Regression & 57.725 & 3 & 19.242 & 35.128 & .000 \\
\hline
\end{tabular}

TABLE V. GOODNESS OF MODEL FIT $\left(\mathrm{R}^{2}\right)$ FOR DEPENDENT VARIABLE IMPROVED ARCHITECTURE QUALITY

\begin{tabular}{|c|c|c|c|c|}
\hline Model & $\bar{R}$ & $\overline{R^{2}}$ & $\begin{array}{l}\text { Adjusted } \\
R^{2}\end{array}$ & $\begin{array}{l}\text { Durbin- } \\
\text { Watson }\end{array}$ \\
\hline $\begin{array}{l}\text { dependent variable: } \\
\text { Higher architecture } \\
\text { quality }\end{array}$ & .796 & .633 & .615 & 1.973 \\
\hline
\end{tabular}

In a second step we analyzed drivers for the observance of EA principles (dependent variable). Again we performed a stepwise explorative regression analysis which yielded four drivers. The first driver is that principles should be defined for business architecture. The second driver is that principles should be centrally defined and approved by the management. The third driver (having a negative coefficient) is that principles are difficult to enforce. And finally the fourth driver states that there should be regular checks for principle's usefulness. The goodness of fit for this model (adjusted $\mathrm{R}^{2}=.696$ ) is even better than in the previous regression analysis. Like for the previous regression analysis, we performed $\mathrm{F}$ test, $t$ test, as well as tests for heterogeneity of variance, autocorrelation, and multi-collinearity without negative indication. 
TABLE VI. DRIVERS FOR OBSERVANCE OF PRINCIPLES

\begin{tabular}{|c|c|c|c|}
\hline \multirow{2}{*}{$\begin{array}{l}\text { Model } \\
\text { (dependent variable: EAP } \\
\text { observed) }\end{array}$} & $\begin{array}{l}\text { Standardized } \\
\text { Coefficients }\end{array}$ & \multirow[b]{2}{*}{$\mathbf{t}$} & \multirow[b]{2}{*}{ Sig. } \\
\hline & Beta & & \\
\hline $\begin{array}{l}\text { EAP defined for business } \\
\text { architecture }\end{array}$ & .268 & 3.096 & .003 \\
\hline $\begin{array}{l}\text { EAP defined centrally and } \\
\text { approved by management }\end{array}$ & .326 & 3.499 & .001 \\
\hline EAP difficult to enforce & -.212 & -3.003 & .004 \\
\hline EAP checked for usefulness & .354 & 3.906 & .000 \\
\hline
\end{tabular}

TABLE VII. MODEL QUALITY (F TEST) FOR DEPENDENT VARIABLE OBSERVANCE OF PRINCIPLES

\begin{tabular}{l|rrrrr}
\hline Model & $\begin{array}{l}\text { Sum of } \\
\text { Squares }\end{array}$ & $\boldsymbol{d f}$ & Mean Square & $\boldsymbol{F}$ & Sig. \\
\hline Regression & 46.584 & 4 & 11.646 & 36.521 & .000 \\
\hline
\end{tabular}

TABLE VIII. GOODNESS OF MODEL FIT $\left(\mathrm{R}^{2}\right)$ FOR DEPENDENT VARIABLE OBSERVANCE OF PRINCIPLES

\begin{tabular}{l|lccr}
\hline Model & $\boldsymbol{R}$ & $\boldsymbol{R}^{2}$ & $\begin{array}{l}\text { Adjusted } \\
\boldsymbol{R}^{2}\end{array}$ & $\begin{array}{l}\text { Durbin- } \\
\text { Watson }\end{array}$ \\
\hline $\begin{array}{l}\text { dependent variable: } \\
\text { EAP observed }\end{array}$ & .846 & .716 & .696 & 1.791 \\
\hline
\end{tabular}

\section{DISCUSSION AND FURTHER RESEARCH}

The few existing publications on EA principles allow for reconstructing their EA definition. While authors focus different aspects of an EA principle definition, they do not contradict each other so that the different definition aspects can be consolidated into a rich EA principle meta-model. For that purpose, a core definition (dealing with the EA principle itself) and an extended definition (dealing with the impact of an EA principle on its environment) is proposed.

After the concept of an EA principle is sufficiently clarified, it can be used to compare practices and obtain knowledge regarding how EA principles are used. Although initial interviews with practitioners indicate that EA principles are a well understood area of managing transformation, further analyses of case studies, however, reveal that only very few organizations consistently apply and manage EA principles. Data obtained in a first EA principle survey of respondents from 70 Swiss and German companies support these initial observations.

Even after EA (management, EAM) approaches and EA(M) tools have successfully expanded their focus from (enterprise-wide) IT architecture to the business side over the last years, this widened scope cannot be observed for EA principles yet. With regard to design activity (and not representation or tooling), EAM success still seems to be limited by a too technically biased, too centralistic, and too bureaucratic approach. Current EAM practice regarding EA principles does not sufficiently focus on effectiveness (missing application advice), is too static (no regular usefulness checks and updates) and is too less customer oriented (no stakeholder involvement, missing business architecture principles).

For a more in-depth analysis of EA principle usage, the 19 questions of our survey need to be grounded-as far as explanatory theory is available and applicable. In addition, the survey needs to be expanded beyond a certain geography area. Furthermore, usage data need to be related not only to context data, but also to perceived EA success. Finally, the analysis should not address EA principles as a whole, but instead should differentiate relevant principle classes. These four directions are avenues for further research.

Although not yet analyzed, our dataset includes further data on the respondents' organizational culture as well as on EA's success in the respective organization. Our hypothesis is that the enforcement difficulties of EA principles (item P.08, highest of all values) are related to the way EA principles are defined and justified. We do not expect, however, to find one best way of EA principle definition and enforcement-but we expect that the efficacy of an approach depends on the organization's culture $[4,11,12]$. This is because design principles restrict the design freedom $[8,15,16]$ of a potentially large group of stakeholders [20, 21, 22, 28, 29]. Organizations have different modes to deal with such restrictions like hierarchical control, rational argumentation or sense making in groups $[23,30]$. In our future work, we will analyze these relations in order give practical advice on how to systematically increase the maturity of EA principles' definition, enforcement, and management processes.

\section{REFERENCES}

[1] S. Aier, C. Fischer, and R. Winter, "Construction and Evaluation of a Meta-Model for Enterprise Architecture Design Principles" in Proceedings of the 10th International Conference on Wirtschaftsinformatik WI 2.011, Zurich, 2011, pp. 637-644.

[2] S. Aier and B. Gleichauf, "Application of Enterprise Models for Engineering Enterprise Transformation" Enterprise Modelling And Information Systems Architectures, vol. 5, no. 1, 2010, pp. 58-75.

[3] F.J. Armour, S.H. Kaisler, and S.Y. Liu, "A Big-Picture Look at Enterprise Architectures" IEEE IT Professional, vol. 1, no. 1/2, 1999, pp. $35-42$.

[4] A.E. Brown and G.G. Grant, "Framing the Frameworks: A Review of IT Governance Research" Communications of the Association for Information Systems, vol. 15, no. May, 2005, pp. 696-712.

[5] S. Buckl, A.M. Ernst, F. Matthes, and C.M. Schweda, "An Information Model for Landscape Management - Discussing Temporality Aspects" in Service-Oriented Computing - ICSOC 2008 Workshops, Berlin, 2009, Springer, pp. 363-374.

[6] A.F. Chalmers, What Is this Thing Called Science?, 3 ed., Buckingham: Open University Press, 1999.

[7] D. Chen and F. Lillehagen, "Enterprise Architectures - Review on Concepts, Principles and Approaches" in 10th International Conference on Concurrent Engineering (ISPE CE 2004), Beijing, 2004, Tsinghua University Press, pp. 1211-1216.

[8] J.L.G. Dietz, Enterprise Ontology - Theory and Methodology, Berlin, Heidelberg: Springer, 2006.

[9] J.L.G. Dietz, Architecture. Building strategy into design, The Hague: Academic Service, 2007.

[10] R. Dubin, Theory Building, New York: Free Press, 1978.

[11] P. Ein-Dor and E. Segev, "Organizational Context and the Success of Management Information Systems" Management Science, vol. 24, no. 10,1978 , pp. 1064-1077. 
[12] F.E. Fiedler, "A Contingency Model of Leadership Effectiveness" Advances in Experimental Social Psychology, vol. 1, 1964, pp. 149190.

[13] C. Fischer, R. Winter, and S. Aier, "What is an Enterprise Architecture Design Principle? Towards a Consolidated Definition" in Roger Lee, ed. Computer and Information Science 2010, Studies in Computational Intelligence, Berlin, Heidelberg: Springer, 2010, pp. 193-205.

[14] A.R. Hevner and S. Chatterjee, Design Research in Information Systems: Theory and Practice, Integrated Series in Information Systems, Vol. 22, Dordrecht, Heidelberg, London, New York: Springer US, 2010.

[15] J.A.P. Hoogervorst, "Enterprise Architecture: Enabling Integration, Agility and Change" International Journal of Cooperative Information Systems, vol. 13, no. 3, 2004, pp. 213-233.

[16] J.A.P. Hoogervorst, Enterprise Governance and Enterprise Engineering, Berlin: Springer, 2009.

[17] IEEE, IEEE Recommended Practice for Architectural Description of Software Intensive Systems (IEEE Std 1471-2000). 2000,

[18] J. Iivari and M. Huisman, "The Relationship between Organizational Culture and the Deployment of Systems Development Methodologies" MIS Quarterly, vol. 31, no. 1, 2007, pp. 35-58.

[19] P. Järvinen, On Research Methods, Tampere, Finland: Opinpajan kirja, 2001.

[20] S. Kurpjuweit and R. Winter, "Viewpoint-based Meta Model Engineering" in Enterprise Modelling and Information Systems Architectures - Concepts and Applications, Proceedings of the 2nd Int'l Workshop EMISA 2007, Bonn, 2007, Gesellschaft für Informatik, Köllen, pp. 143-161.

[21] S. Kurpjuweit and R. Winter, "Concern-oriented Business Architecture Engineering" in Applied Computing 2009 - The 24th Annual ACM Symposium on Applied Computing, 2009, ACM, pp. $265-272$.

[22] R. Lagerström, J. Saat, U. Franke, S. Aier, and M. Ekstedt, "Enterprise Meta Modeling Methods - Combining a StakeholderOriented and a Causality-Based Approach" in Enterprise, BusinessProcess and Information Systems Modeling, Proceedings of the 10th International Workshop BPMDS and 14th International Conference EMMSAD at CAiSE 2009, Berlin, 2009, Springer, pp. 381-393.

[23] D.E. Leidner and T. Kayworth, "A Review of Culture in Information Systems Research: Toward a Theory of Information Technology Culture Conflict" MIS Quarterly, vol. 30, no. 2, 2006, pp. 357-399.

[24] M. Leppänen, K. Valtonen, and M. Pulkkinen, "Towards a Contingency Framework for Engineering an Enterprise Architecture Planning Method" in Proceedings of 30th Information Systems Research Seminar in Scandinavia (IRIS 2007), 2007.

[25] Å. Lindström, "On the Syntax and Semantics of Architectural Principles" in 39th Annual Hawaii International Conference on
Systems Sciences, Los Alamitos, CA, USA, 2006, IEEE Computer Society.

[26] D.L. Morgan, Focus Groups as Qualitative Research, 2 ed., Thousand Oaks: Sage Publications, 1997.

[27] M. Mykhashchuk, S. Buckl, T. Dierl, and C. Schweda, "Charting the Landscape of Enterprise Architecture Management" in Proceedings of the 10th International Conference on Wirtschaftsinformatik WI 2.011, Zurich, 2011, pp. 570-577.

[28] E. Niemi, "Enterprise Architecture Stakeholders - A holistic view" in The 13th Americas Conference on Information Systems (AMCIS 2007), 2007.

[29] M. Op't Land, E. Proper, M. Waage, J. Cloo, and C. Steghuis, Enterprise Architecture - Creating Value by Informed Governance, Berlin: Springer, 2009.

[30] R.E. Quinn and J. Rohrbaugh, "A competing values approach to organizational effectiveness" Public Productivity Review, vol. 5, no. 2, 1981, pp. 122-140.

[31] G.L. Richardson, B.M. Jackson, and G.W. Dickson, "A PrincipleBased Enterprise Architecture: Lessons From Texaco and Star Enterprise" MIS Quarterly: Management Information Systems, vol. 14, no. 4, 1990, pp. 285-403.

[32] J. Schelp and R. Winter, "Language Communities in Enterprise Architecture Research" in Diversity in Design Science - 4th Conference on Design Science Research in Information Systems and Technologies (DESRIST2009), Philadelphia, PA, USA, 2009, ACM, pp. 1-10.

[33] M. Schönherr, "Towards a Common Terminology in the Discipline of Enterprise Architecture" in Service-Oriented Computing - ICSOC 2008 Workshops, Sydney, 2009, Springer, pp. 400-413.

[34] D. Stelzer, "Enterprise Architecture Principles: Literature Review and Research Directions" in Service-Oriented Computing. ICSOC/ServiceWave 2009 International Workshops, Stockholm, Sweden, November 23-27, 2009, Revised Selected Papers, Berlin, 2010, Springer, pp. 12-21.

[35] The Open Group, TOGAF Version 9 - The Open Group Architecture Framework (TOGAF), The Open Group, 2009.

[36] W.L. Wallace, Principles of Scientific Sociology, New York: Aldine Publishing Company, 1983.

[37] M. Wilkinson, "Designing an "Adaptive" Enterprise Architecture" BT Technology Journal, vol. 24, no. 4, 2006, pp. 81-92.

[38] R. Winter and R. Fischer, "Essential Layers, Artifacts, and Dependencies of Enterprise Architecture" Journal of Enterprise Architecture, vol. 3, no. 2, 2007, pp. 7-18. 